\title{
OS HERDEIROS DA "FAZENDA BOM SUCESSO" E A POPULAÇÃO NEGRA NA HISTÓRIA DE BELO HORIZONTE (MG)
}

\author{
JOSEMEIRE ALVES PEREIRA \\ UNIVERSIDADE ESTADUAL DE CAMPINAS (UNICAMP)
}

\begin{abstract}
RESUMO: O artigo discute, por meio da análise de documentação policial e jurídica, a presença e atuação de um grupo de famílias negras estabelecidas, desde meados do século XIX, no território em que foi estabelecida a nova Capital de Minas Gerais, Belo Horizonte. Entre 1913 e 1917, essas famílias envolveram-se em um conflito, no qual partiam em defesa de seus direitos sobre terrenos de uma fazenda herdada por seus antepassados, quando esses ainda se encontravam em condição de escravidão. O episódio apresenta elementos que evidenciam a existência e a agência de sujeitos em geral negligenciados nas narrativas históricas e historiográficas sobre a cidade.
\end{abstract}

PALAVRAS-CHAVE: Pós-Abolição; Negros; Belo Horizonte (MG).

ABSTRACT: The article discusses the agency of black families in Belo Horizonte, capital of Minas Gerais. These families, were involved in an important conflict, occurred between 1913 and 1917, in defense of their rights on a land farm inherited by their ancestors since mid-nineteenth century. The episode refers to subjects neglected on historical narratives about the town.

KEY-WORDS: Post Abolition; Black people; Belo Horizonte (MG). 
A necessidade de transferência da sede administrativa de Minas Gerais para outra localidade, debatida intensamente pelas classes políticas, durante as últimas décadas do século XIX, é creditada às mudanças econômicas e políticas engendradas no País a partir dos processos que resultaram na Abolição da escravatura e na instituição do regime republicano ${ }^{1}$. Tito Flávio Rodrigues de Aguiar $^{2}$ afirma, a propósito, que os debates políticos que precederam a mudança da capital do Estado, entre as décadas de 1880 e 1890, evidenciavam preocupações das elites políticas e econômicas quanto à necessidade de criação de um novo centro administrativo, que propiciasse a superação do atraso no desenvolvimento em relação aos centros econômicos do País - Rio de Janeiro e São Paulo -, que atraíam, inclusive, municípios mineiros situados próximos às fronteiras com essas regiões, constituindo eminente risco de desagregação político-administrativa do Estado de Minas Gerais. Em tais debates, a noção de "modernização mineira" passava a ser defendida, remetendo, então, à defesa de uma política favorável ao progresso econômico do Estado. A nova Capital teria surgido, assim, como elemento fundamental deste projeto de "modernização".

Como parte da estratégia de enfrentamento aos riscos de desagregação político-administrativa e estagnação econômica do Estado, a então Cidade de Minas emergia dos Planos do Engenheiro Aarão Reis ${ }^{4}$, a partir de 1894, e impunha-se, sob o signo da modernidade e do progresso, sobre a cidade colonial representada pela antiga Ouro Preto e pelo Arraial do Curral Del Rei, sobre o qual foi construída a nova sede política e administrativa.

Para a criação da nova cidade, foram desapropriados e devidamente remunerados os antigos proprietários de terra do Arraial, que se instalaram em regiões relativamente próximas ao futuro núcleo urbano da nova cidade $^{5}$. Quanto à população outrora ali escravizada e/ou liberta, a despeito de sua

\footnotetext{
${ }^{1}$ Os dados utilizados neste artigo foram obtidos no âmbito de pesquisa para Doutorado em História, subsidiada com recursos da Fapesp.

${ }^{2}$ Cf. AGUIAR, Tito Flávio Rodrigues de. Vastos subúrbios da nova capital: formação do espaço urbano na primeira periferia de Belo Horizonte. 2006. 443 p. Tese (Doutorado em História) Faculdade de Filosofia e Ciências Humanas, Universidade Federal de Minas Gerais, Belo Horizonte, 2006, p. 34.

${ }^{3}$ Ver também: DULCI, Otávio Soares. Política e recuperação econômica em Minas Gerais. Belo Horizonte: Ed. UFMG, 1999.

${ }^{4}$ Cf. a respeito: SALGUEIRO, Heliana Angotti. Engenheiro Aarão Reis: o progresso como missão. Belo Horizonte: Ed. Fundação João Pinheiro. Centro de Estudos Históricos e Cultuais, 1997. (Col. Centenário).

${ }^{5}$ Cf. ROMANO, Olavo. Muito além da cidade planejada: uma contribuição à História da região nordeste da Capital. Belo Horizonte: Colégio Magnum Agostiniano, s/d.
} 
relevância sobre o total da população, no passado ${ }^{6}$, dela aparecem alguns raros indícios na narrativa do historiador Abílio Barreto ${ }^{7}$ sobre o Arraial, de onde emerge, em geral, por meio de personagens secundários, tais como um escravizado fugido que teria assassinado um major, ou como outros, descritos em atividades laborais.

Quase nada sabemos sobre o destino dessas pessoas, depois de emancipadas por meio da Lei n 3.353, de 13/5/1888 ("Lei Áurea"), ou mesmo antes, mediante outras formas legais de aquisição da liberdade de que se apropriaram ou foram beneficiárias ${ }^{8}$. Teriam continuado a trabalhar com os antigos senhores, como parece ter sido recorrente no imediato período pósabolição? ${ }^{9}$ Em que condições? Teriam migrado para outras localidades, como observamos ocorrer, em diversas regiões do País ${ }^{10}$ e também em outros países $^{11}$, em virtude dos processos abolicionistas? Teriam participado da construção da nova Capital?

Essas são questões que ainda demandam atenção nos estudos sobre a história de Belo Horizonte, no panorama dos estudos sobre as experiências de liberdade vivenciadas no País. Naqueles estudos, o que se ressalta, em regra, é o esforço dos idealizadores da nova capital em associar a ela uma imagem de progresso, vinculada à República. Assim, efetuou-se a criação de uma memória histórica da cidade que não faz referência significativa à presença da população

\footnotetext{
${ }^{6}$ Em edição de 1911 do Anuário Estatístico de Minas Geraes, Nelson de Senna, preocupado em avaliar os números referentes à população branca do estado, faz menção a um primeiro recenseamento realizado na Capitania das Minas Gerais, em 1776, destacando a baixa proporção de brancos na Comarca do Rio das Velhas, à qual pertencia, então, a região de Sabará e o povoado do Curral Del Rei. Na comarca haviam sido registrados, então, apenas 14.394 brancos "contra 85.182 mestiços e pretos". (Cf. MINAS GERAES. Anuário Estatístico. Belo Horizonte: Imprensa Oficial. 1911, p. 255; MINAS GERAES. Anuário Estatístico. Belo Horizonte, Secretaria da Agricultura. 1925. Ano I, 1921/Vol. 2).

${ }^{7}$ Cf. BARRETO, Abílio. Belo Horizonte: memória histórica e descritiva. Ed. atual. rev. e anotada. Belo Horizonte: Fundação João Pinheiro/Centro de Estudos Históricos e Culturais, 1996. v.1.

${ }^{8}$ Ibid.

${ }^{9}$ Cf. SOUZA, Edinelia Maria de Oliveira. História Oral, memórias e campesinato negro/mestiço na Bahia pós-abolição. In: História Oral, v. 16, n. 2, p. 55-71, jul./dez., 2013. Ver também: SOUZA, Edinelia Maria de Oliveira. Cruzando memórias e espaços de cultura: Dom Macedo Costa, Bahia (1930-1960). In: Projeto História, São Paulo, (18) mai. 1999. Fenômeno semelhante foi abordado para a Região Sudeste do País, nas pesquisas de Ana Lugão Rios e Hebe Mattos, publicadas no livro Memórias do cativeiro: família, trabalho e cidadania no pósabolição.

${ }^{10}$ Cf.: FRAGA FILHO, Walter. Mendigos, moleques, vadios na Bahia do século XIX. São Paulo, SP: Hucitec, 1996; Encruzilhadas da liberdade: histórias de escravos e libertos na Bahia (18901910). Campinas, SP: Editora da Unicamp, 2006; Migrações, itinerários e esperanças de mobilidade social no recôncavo baiano após a Abolição. Cadernos AEL, v. 14, n. 26, 2009. Ver também: RIOS, Ana Lugão; MATTOS, Hebe. Memórias do cativeiro: família, trabalho e cidadania no pós-abolição. Rio de Janeiro: Ed. Civilização Brasileira, 2005.

${ }^{11}$ Cf. FONER, Eric. O significado da liberdade. Revista Brasileira de História. v. 1, n. 16, p. 9-36. São Paulo, mar-ago/1988a; Nada além da liberdade: a emancipação e seu legado. Rio de Janeiro/Brasília: Paz \&Terra/CNPq, 1988b. Ver também: COOPER, Frederick et al. (Org.). Além da liberdade: investigações sobre raça, trabalho e cidadania em sociedades pós-emancipação. Rio de Janeiro: Civilização Brasileira, 2005.
} 
negra $^{12}$. Afinal, poder-se-ia argumentar, Belo Horizonte, ao contrário das principais sedes administrativas do País, à época, nascia sem a indelével marca da escravidão, que é, em geral, a via por meio da qual se faz referência à população negra. Além disso, pode-se alegar, os principais registros por meio dos quais o assunto poderia ser abordado - em especial os de cunho demográfico - não relatam a cor.

Contudo, em meio aos aparentes silêncios das fontes, que justificariam a invisibilidade dos não brancos nas narrativas que dão a conhecer a produção do espaço, as sociabilidades e a vida política da cidade de Belo Horizonte em sua historicidade, algumas fontes têm se revelado potencialmente relevantes, no esforço de conhecimento sobre a presença dos "silenciados" na história da cidade. É o caso de registros hospitalares, documentação policial, registros orais, iconografia, dentre outros, que atestam - inclusive estatisticamente, a despeito dos limites das fontes policiais e hospitalares onde é possível encontrar esse tipo de informação -, uma presença constante, crescente e percentualmente superior de "pretos" e "mestiços" na população da Capital, durante a primeira metade do século XX. É que para lá, desde o advento de sua construção, passou a afluir grande contingente de trabalhadores, dentre os quais provavelmente muitos descendentes de pessoas egressas da escravidão ${ }^{13}$.

Não obstante a relevância da população de migrantes, também a participação de antigos habitantes pretos e, provavelmente, mestiços do Arraial do Curral Del Rei nessa população negra da cidade nos é atestada pela descoberta de documentos, junto aos registros policiais - e, a partir destes, aos jurídicos -, de um grupo constituído por famílias negras que viviam na região, desde meados do século XIX, pelo menos. Trata-se de documentos que informam sobre a existência dos herdeiros de uma antiga fazenda, situada no território da Nova Capital, que fora finalmente inaugurada em 1897. As vozes dos "negros" da Fazenda Bom Sucesso, direta ou indiretamente registradas nesta documentação, testemunham experiências de liberdade construídas pela população negra, por meio da relação com a terra, entre os tempos da vida no velho Arraial do Curral Del Rei - ainda antes de abolida a escravidão - e os novos tempos que se anunciavam com a criação da cidade que se projetava republicana e com desejos de modernidade.

\footnotetext{
12 A expressão negro/a é utilizada, aqui, para designar pessoas denominadas, nas fontes consultadas, ora como negros/as, ora como pretos/as e, ainda, por referência à população constituída de pessoas classificadas, em outras fontes do período, como pretas e mestiças.

${ }^{13} \mathrm{O}$ historiador Tarcísio Botelho, analisando o perfil demográfico de Belo Horizonte, na primeira metade do século XX, afirma ter havido, no período entre 1890 e 1940, um aumento da população negra na região central de Minas Gerais, onde está localizada a capital. Apesar da dificuldade de mensurar nos registros paroquiais por ele analisados, a caracterização da população por cor/raça, o autor estima que a presença de descendentes de africanos na capital, embora reduzida nos primeiros anos, tendeu a aumentar, em decorrência do fluxo migratório interno. Cf. BOTELHO, Tarcísio R. A migração para Belo Horizonte na primeira metade do século XX. Cadernos de História, Belo Horizonte, v. 9, n. 12, p. 11-33, $2^{\circ}$ sem. 2007.
} 


\section{Um conflito como ponto de partida...}

Fazia já, provavelmente, algum tempo que Arthur Agostinho dos Santos chegara a Belo Horizonte, vindo de Ouro Preto, provavelmente atraído pelas oportunidades de trabalho que a recém-inaugurada Capital de Minas Gerais parecia oferecer. Sobre a data precisa de sua chegada à nova cidade ou sobre as experiências que ele ali viveu, não nos é dado conhecer por meio das fontes disponíveis. Sabemos, contudo, que em 1916, Agostinho, então com 26 anos e já casado, encontrava-se trabalhando nas terras da Fazenda Bom Sucesso, onde residia. E que no dia 31 de outubro daquele ano, por volta das 12 horas, quando cultivava a lavoura da dita Fazenda - segundo contou no dia 3 de novembro do mesmo ano, em depoimento ao delegado Waldemar Loureiro testemunhou o seguinte ${ }^{14}$ :

[viu] descendo o morro com direção á fazenda do Bom Successo J. G. R., F. G. R. e A. S. e subindo o morro em direção contraria, A. C. acompanhado de seis negros dos herdeiros de André Villa Nova, todos armados, que ao chegarem estes últimos na encrusilhada [sic] denominada do Taquaral tomaram a frente cercando-os aos outros que vinham descendo; momentos depois o depoente ouviu um tiro e por medo escondeu em uma grota, de onde só mais tarde se retirou, nada sabendo do que se passou... ${ }^{15}$.

O tiro fatal escutado por Arthur Agostinho partira de uma carabina Winchester, calibre 44, e fora disparado por F. G. R., à época com 18 anos de idade, contra o negociante italiano naturalizado brasileiro A. C., também casado, de 44 anos. O episódio inscrevia-se como parte do desfecho trágico de uma disputa que se arrastava já há alguns anos, entre a família G. R. e um grupo formado por cerca de 43 famílias negras, constituídas por 79 pessoas, reconhecidas como trabalhadores herdeiros de André Nogueira Villa Nova. 0 objeto dessa disputa era uma gleba dos terrenos da fazenda Bom Sucesso, que se localizava para além do perímetro urbano da nova Capital, há cerca de 16 quilômetros, na região sul da cidade, e que divisava com o município de Villa Nova de Lima.

\footnotetext{
${ }^{14}$ Em respeito ao acordo de sigilo que, conforme política do Tribunal de Justiça de Minas Gerais, condicionou a consulta aos autos do processo judicial a que faremos referência, os nomes dos envolvidos não serão explicitados. Exceção para os herdeiros da Fazenda Bom Sucesso e demais depoentes, que participam como testemunhas durante o processo, mas que são mencionadas também na documentação policial. Esse critério não se aplicará às demais fontes consultadas, por não sofrerem sansões similares, por parte da instituição arquivística a que estão vinculados.

${ }^{15}$ Tribunal de Justiça de Minas Gerais (a partir daqui referenciado apenas pela sigla TJMG). $1^{\text {a }}$ Vara Criminal. Processo Criminal No 02490747829-1, maço 33, p. 28-28v. (Mantida a grafia original, como nas demais citações que seguem). Grifos meus.
} 
A Bom Sucesso pertencera a Gertrudes Antônia da Fonseca, que legara parte dos terrenos - cerca de 17.244 hectares $^{16}$ - ao usufruto dos referidos trabalhadores, em testamento datado de 7 de janeiro de 1831. Em 1856, seu esposo, André Nogueira Villa Nova, vendeu parte da fazenda a J. G. R. patriarca da família dos dois principais acusados pelo crime contra A. C. -, e nomeou como herdeiros da outra parte da Bom Sucesso a Rita ("Parda"), Joaquim ("Creoulo"), Feliciano ("Pardo"), e outros trabalhadores escravizados que atuaram na Fazenda desde, pelo menos, a primeira metade do século $\mathrm{XIX}^{17}$.

De acordo com o que podemos observar do relato de testemunhas que depuseram por ocasião da investigação policial que resultou no inquérito enviado à Promotoria de Justiça de Belo Horizonte, pelo delegado Waldemar Loureiro, bem como das que o fizeram durante o processo de julgamento dos réus, assim como da documentação anexada ao Processo Criminal referente ao caso, em junho de 1914, um dos herdeiros da Bom Sucesso, descendente de uma das famílias beneficiárias no testamento de Gertrudes Fonseca, Manoel Luiz Maria, juntamente com sua mulher, propuseram contra H. G. R. e outras pessoas de sua família - e também contra The St. John d'El Rey Mining Companhy Limited $^{18}$-, uma ação possessória, junto ao Tribunal da Relação do Estado de Minas Gerais, para reivindicar uma parte dos terrenos que estariam sendo indevidamente ocupados pelos $\mathrm{G}$. R. Cópias de autos cíveis que integram o Processo Criminal produzido por ocasião do julgamento dos acusados informam-nos de que a sentença, bem como a resposta aos recursos embargados pelos apelantes, foram desfavoráveis a Manoel Luiz e sua esposa, Ana Apolinária ${ }^{19}$. Indicam mais, que os G. R. também acionaram Manoel e sua esposa, por meio do mesmo Tribunal da Relação. Também nesse caso, os G. R. foram beneficiados ${ }^{20}$.

Ao que indicam as fontes, após essas derrotas na Justiça, Manoel Luiz Maria procurou A. C., negociante conhecido e considerado bem relacionado na cidade, para que este lhe auxiliasse na defesa dos interesses dos herdeiros. Algumas lacunas, entretanto, se apresentam acerca da relação entre A. C. e os herdeiros - desde quando e em que circunstâncias se conheciam? Quais teriam sido os interesses que mobilizaram A. C. nessa parceria? O que levava Manoel Luiz e os seus, afinal, a confiarem nele?

\footnotetext{
${ }^{16}$ Ibid., p. $115-116 v$.

17 Ibid. Arquivo Público Mineiro (APM). Fundo Chefia de Polícia. POL 8, Cx.02-Pc.14-25, Ocorrências Policiais - 017.04. Cópia do Relatório apresentado pelo Delegado de Polícia ao Juiz Municipal do Termo.

${ }^{18}$ A The St. John d'El Rey Mining Companhy Limited, também conhecida como "Mina de Morro Velho", foi objeto de estudo do pesquisador Douglas Cole Libby, durante o Mestrado em Ciência Política, pela UFMG nos anos 1970. A pesquisa resultou no livro Trabalho escravo e capital estrangeiro no Brasil: o caso do morro velho, publicado em 1984.

${ }^{19} \mathrm{O}$ nome de Ana Apolinária não é mencionado nos documentos até então em apreço, sendo ela referida apenas nos seguintes termos: "Manoel Luiz Maria e sua esposa". Contudo, aparecerá como outorgante e identificada como esposa de Manoel Luiz Maria, em uma procuração, da qual trataremos a seguir.

${ }^{20}$ TJMG - PROCESSO CRIMINAL No 02490747829-1, maço 33 - Cópia de Autos Cíveis, p. 126.
} 
Durante a defesa dos acusados, o advogado da família G. R., Gudesteu Pires de Sá, optou por uma estratégia que incluía forjar um argumento de que o italiano não seria homem de bom caráter e que havia usado de má-fé para manipular os herdeiros, sendo o principal responsável por desordens e esbulhos praticados nas terras em litígio, consideradas pelos G. R. como sendo de sua propriedade. Como suporte a esse argumento, por meio do qual buscava atenuar a culpa dos G. R., alegando defesa da honra e do patrimônio, Pires de Sá apresentou diversos documentos, dentre os quais se destaca uma carta do advogado da The Saint Jonh d'El Rei Mining Companhy, Flávio F. dos Santos, referindo-se à reivindicação feita pelos herdeiros no Tribunal da Relação, quanto às terras que a mineradora estaria ocupando indevidamente. Afirma, então, Santos:

A Companhia do $\mathrm{M}$ [orro] Velho sempre procurou agir legalmente nestas questões e, apesar do apoio das autoridades e do julgado em seu favor, tudo foi em vão á [sic] vista da jacuncia, truculência e actos de força de A. C., que tractou de agir, abusando da ignorância dos tais herdeiros, que se tornaram instrumento dócil e fácil em suas mãos, locupletandose á sua custa, como se vê claramente dos autos de desapropriação [dos quais consta a Procuração]. É incrível o que praticou $A$. C., aqui, á júri das autoridades ${ }^{21}$.

A percepção dos herdeiros como incapazes de agirem por si próprios, expressa no fragmento acima, é recorrente em outros depoimentos de testemunhas favoráveis aos G. R. Esse aspecto é bastante eloquente quanto às relações sociais estabelecidas entre as famílias negras herdeiras da Fazenda Bom Sucesso e os demais grupos da região e será retomado adiante. Por ora, contudo, é importante tomar em consideração outro documento utilizado por Pires de Sá e que nos ajuda a compreender acerca das relações entre os herdeiros e A. C. Trata-se de uma Procuração, datada de 16 de agosto de 1915, por meio da qual o negociante italiano passara a representar os primeiros que, nos seguintes termos:

nomeavam e constituíam seu bastante procurador a A. C.[sic], onde com poderes [...] especialmente para tratar de qualquer acção cível ou crime, em que forem autores ou réos, assistentes ou appoentes, podendo para isso requerer $\mathrm{e}$ promover, judicial ou extra-judicialmente, variar e desistir de acção, citar e ser citado, reservando-lhes no entanto 0 recebimento da primeira citação; defender os seus direitos em todas as instancias e tribunaes; [...]; assignar quaisquer termos, mesmo de juramento, confissão ou desistência, acordo ou negação; interpor e arrazoar os recursos leaes; nomear e

\footnotetext{
${ }^{21}$ Carta do advogado Flávio F. Santos a Gudesteu Pires de Sá, em 22 de janeiro de 1917. TJMG.

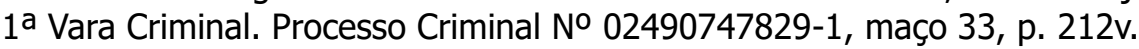


aprovar louvados, oferecer quesitos, requerer licitação, adjudicação e remissão; prosseguir nas execuções de sentenças; produzir, inquerir e reperguntar testemunhas; dar de suspeito a quem Ihe parecer; assignar quaisquer escripturas de compra e venda, dar recibos e quitação; entrar na posse dos terrenos demandados; acompanhar e responder por elles qualquer acção que Ihe fôr proposta; desistir e renunciar quaisquer dos seus direitos patrimoniais, no todo ou em parte, conferindo-Ihe para isso poderes especiaes, requerer 0 desentranhamento de quaisquer documentos; [...]; tratar e se entender com o Governo deste Estado sobre a liquidação, cobrança e recebimento do preço e valor da indemnização das aguas e seus manaciaes da Fazenda do Bom Successo, próximo a esta Capital, que lhes pertence, bem como dos terrenos que compõem as vertentes das mesmas aguas, nos limites determinados no decreto de desapropriação baixado pelo Governo do Estado, podendo o seu dito procurador usar de todos os recursos legaes para cobrar amigável ou judicialmente, como julgar mais conveniente, o valor da imdemnização, propor as acções[...] que se tornarem necessárias a esse fim, acceitar Juizo Arbitral, transigir em juízo e fora dele receber e dar quitação, levantar depósitos ou causões, receber juros, fazer transferências de títulos nas repartições publicas Estadoaes, Federaes ou Municipaes; e, finalmente, substabelecer esta procuração, se convier, no todo ou em parte, a um ou mais de um, especificando neste caso quaes poderes e para que acção substabelece a um e a outro, sendo duas as pessoas, com ou sem reserva de poderes ${ }^{22}$.

A gama de poderes concedidos ao procurador, como atesta o fragmento de documento em apreço era, de fato, muito ampla. No limite, a atuação de A. C. poderia vir a constituir risco ao patrimônio dos próprios herdeiros. $E$ pode-se aventar que ele tenha se valido, em alguma medida, do fato de que cerca de 68 das 79 pessoas nomeadas na Procuração como outorgantes da procuração não sabiam ler nem escrever, tendo sido o mesmo documento assinado pelas testemunhas, a rogo.

Não obstante, não há indícios, na documentação, de que A. C. tenha efetuado qualquer prática que prejudicasse seus representados, no período entre o momento da assinatura da procuração e o de sua própria morte, pouco mais de um ano depois. A despeito de a defesa buscar construir a imagem de que os herdeiros promoviam desordens em terreno dos G. R. a mando de A. C., observamos nas entrelinhas dos documentos policiais e judiciais $e$, especialmente, nos depoimentos de Manoel Luiz Maria, Joaquim Luiz e mesmo em alguns testemunhos de trabalhadores empregados pelos G. R., elementos que nos propõem uma interpretação mais abrangente acerca da atuação destes últimos em defesa de suas propriedades.

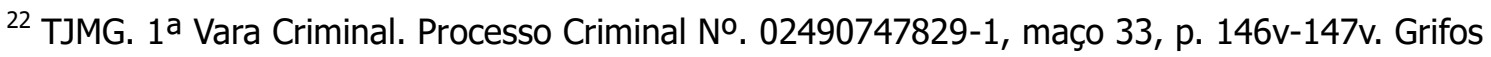
meus e no original.
} 


\section{"Pela lei, justiça e razão": as lutas de Manoel Luiz Maria e seus companheiros}

"Um pobre velho, preto e muito trabalhador" - assim referia-se, em 1902, o Delegado de Polícia da 2a Circunscrição da Capital, Arthur Andrade, a Manoel Luiz Maria ${ }^{23}$, em um ofício dirigido ao Chefe de Polícia do Estado de Minas Gerais. O documento em questão integrava um Inquérito Policial aberto sob ordens do mesmo Chefe de Polícia, para apurar violência e abuso de autoridade cometidos pelo Suplente de Subdelegado de Polícia do então Distrito do "Barreiro", contra Manoel Luiz Maria. A queixa partira do próprio Manoel, que enviara diretamente ao Chefe de Polícia, uma carta provavelmente redigida por alguém de sua confiança, em que denunciava ter sido "maltratado com injúria pública" e privação de liberdade "por prisão sem crimes e sem mostrada culpa", o que prejudicava "os interesses laboriosos das lides" de sua profissão, causando-Ihe "grandes prejuízos"; tudo por parte do Suplente de Subdelegado. Ao fim do documento, Manoel Luiz diz esperar que a autoridade a quem se dirigia, então, tomasse as providências necessárias "pela lei, justiça e razão"; e declarava ser "pobre e pai de família, [com] grande número de filhos e sem recurso algum". E insistia: "Peço a V. Exa. que pelo vosso criterioso caráter, leve a minha queixa em atitude de consideração para o bem de todos e ao mesmo tempo que seja [isto] admitido a bem do serviço público"24.

Encarregado de apurar o caso, em 27 de outubro do mesmo ano, o Delegado Arthur Andrade passou a ouvir os envolvidos e as testemunhas, em 10 de novembro. Nessa ocasião, Manoel Luiz, então com 40 anos, compareceu à Delegacia de Polícia da $2^{a}$ Circunscrição da Capital e detalhou alguns aspectos da denúncia que enviara por meio da carta acima. Declarou que, no dia 10 de outubro daquele ano de 1902, quando trabalhava em casa, foi abordado por um dos soldados da Subdelegacia do Barreiro, intimando Manoel a ir à presença do Suplente de Subdelegado Henrique de Paula Castro. Como não tivesse cometido crime algum e estando ocupado com seu trabalho, naquele momento, Manoel indagou ao soldado se quem o mandava chamar era o Capitão Antônio Pinto, "a quem [conhecia] como Subdelegado", ao que foi respondido que quem ordenava a presença dele à Subdelegacia era o Suplente, Henrique de Paula Castro, a quem Manoel devia certa importância em dinheiro. Entendendo que o motivo da intimação era uma provável cobrança por parte do Subdelegado e como não tinha meios para efetuar o pagamento devido, naquela ocasião, pediu ao soldado "que dissesse a Henrique que no dia seguinte lá iria a fim de pagar-Ihe ${ }^{\prime 25}$. Entretanto, pouco tempo depois Manoel foi novamente abordado por aquele e mais um policial, que the deram voz de prisão e o conduziram à presença de Henrique. Este, tendo perguntado ao preso se conhecia o motivo da prisão, diante de negativa, afirmou a Manoel que o mandara prender "para

\footnotetext{
${ }^{23}$ APM - FUNDO CHEFIA DE POLÍCIA -POL8 Cx:24 PC: 06 - Belo Horizonte [1915-1916].

${ }^{24}$ Ibid.

${ }^{25}$ APM - FUNDO CHEFIA DE POLÍCIA - POL8 Cx:24 PC: 06 - Belo Horizonte [1915-1916]. 
ele ficar sabendo que era uma autoridade que o tinha mandado chamar, e para que não abusasse, como muitos outros" ${ }^{26}$.

O caso foi arquivado, por ordem do Chefe de Polícia, mesmo diante das declarações do próprio Subdelegado do Barreiro que, do mesmo caso ciente e confirmando o depoimento de Manoel Luiz, afirmou que "não havia razão bastante para o seu suplente assim proceder"27. Não obstante, o que se destaca nessa ocorrência, é o registro que dela decorre, sobre a agência de Manoel Luiz Maria ante o que ele, um homem negro, lavrador, não alfabetizado, compreendia ser um abuso de poder cometido contra a sua pessoa.

A carta de Manoel enviada ao Chefe de Polícia, não casualmente, estava anexada a um Inquérito Policial datado de julho de 1915, em que, pela primeira vez, deparamos com um registro documental que atesta o início dos conflitos entre os herdeiros da Fazenda Bom Sucesso e a família G. R. Essa carta e o Inquérito Policial de 1902, faziam parte da investigação feita, na ocasião, pelo delegado da $2^{a}$ Delegacia Auxiliar de Polícia, a partir de ofício do Subdelegado de Polícia do 90 Distrito Policial - a antiga Subdelegacia do Barreiro -, de 6 de julho de 1915, em que este apresenta denúncia contra Manoel Luiz Maria e outros 24 homens que seriam "liderados" por ele, na qual se lê:

Chegando ao meu conhecimento que Manoel Luiz Maria e outros pretendiam demolir uma cerca feita pelo Senr J. G. R. em terreno litigioso entre elles [...], fui ante-hontem no logar denominado Bom Sucesso, onde se dava a questão e procurando, na ausência de Manoel Luiz, o seu filho Joaquim Luiz, o exhortei a não por em pratica o que pretendiam e se não fosse a prudência dos parentes e amigos do Snr J. G. R., que attendendo aos meus conselhos, não reagiram contra a agressão, teria se dado hontem um conflito de gravissimas consequencias, pois, Manoel Luiz e seu filho Joaquim, desattendendo aos meus conselhos e chefiando os individuos[...], todos armados e em attitude aggressiva, demoliram a referida cerca, mudando-a para ponto diverso, onde lhes convinha, sem que eu nada podesse fazer $[\ldots]^{28}$.

Em contraste com os depoimentos de Joaquim Luiz Marcelino e outros envolvidos, como se verá, o fragmento acima indica o quão parcial apresentavase a atuação da autoridade policial local, em favor dos G. R. Mas comecemos pelo depoimento do denunciante, J. G. R., que se dirigindo ao Delegado Especial de Polícia, Arthur Furtado, em 7 de julho de 1915, afirmou:

que sendo senhor e possuidor de uma sórte de terras naquella localidade, de annos a esta parte, tem tido diversas demandas com alguns moradores nas mesmas terras, $[. .$.$] ; que$ ultimamente tendo o depoente tocado uma demanda em Juiso

\footnotetext{
${ }^{26}$ Ibid.

${ }^{27}$ Ibid.

${ }^{28}$ APM - FUNDO CHEFIA DE POLÍCIA. Ocorrências Policiais. POL8 Cx:24 PC: 05-Belo Horizonte [1915], p. 4.
} 
com os moradores das ditas terras, foi o direito do declarante reconhecido por sentença do Tribunal da Relação do Estado, onde os seus contendores comndenados ainda ao pagamento das custas, indo o oficial de Justiça intimal-os da sentença no dia tres do corrente; que hontem, seis do corrente, as onse horas da manhã; Manoel Luiz Maria, a frente de mais vinte e quatro companheiros, foram no logar onde se acha a cerca que divide os terrenos do declarante com os de H.G. R., cerca essa de arame farpado e arrancaram a mesma, levando parte para um logar e outra parte deixaram estragada no chão... ${ }^{29}$.

Aparecem aqui elementos que corroboram o que já foi mencionado acerca das disputas que se desenvolveram em torno do terreno em disputa. Até 1912, aparentemente, as relações entre os herdeiros e os G. R. pareciam dar-se sem conflitos, até que os primeiros observaram que os G. R. invadiam terras que os herdeiros entendiam serem suas; a tal ponto estavam disto convencidos que interpelaram os invasores em Juízo, como vimos. Mover uma ação possessória contra os G. R. parece ter sido o primeiro instrumento de que os herdeiros, representados por Manoel Luiz Maria e Ana Apolinária, muniram-se para tentar resolver o problema. De modo que, sentindo-se injustiçados com a sentença que favorecia os invasores, mas entendendo que o processo ainda estava em aberto, trataram de agir em defesa de suas propriedades arrancaram a cerca e a reposicionaram ao lugar de origem. Note-se que, neste episódio, não há menção à figura do italiano A. C. - o que não nos autoriza a afirmar que não havia relações entre ele e os herdeiros até então.

Cabe notar ainda, um detalhe do depoimento de J. G. R., acima, em que ele afirma ter ido um oficial de Justiça intimar os herdeiros da sentença perdida por estes e pela qual haviam sido, ainda, condenados a pagar as custas, três dias antes do episódio da cerca. Analisando as cópias dos autos referentes à ação movida por Manoel e Ana Apolinária contra os G. R., observamos que, de fato, no dia 10 de abril de 1915 há registro de sentença desfavorável aos herdeiros e em benefício dos G. R., quanto à chamada ação de força velha movida pelos primeiros contra os últimos. Manoel Luiz parece ter recorrido da sentença, tendo sido o recurso denegado no dia 17 de abril. No dia 28 do mesmo mês e ano, a Câmara Civil do Tribunal da Relação julgou procedente uma ação de força nova movida pelos G. R. contra Manoel e seus familiares, em 23 de junho de 2014. Em $1^{\circ}$ de junho de 1915, o advogado dos G. R., Gudesteu Pires de Sá, encaminhava uma Petição de Execução de Sentença, em nome de Maria G. R. e outros, ao Juiz de Direito da Capital. Em 16 de junho e 17 de julho, respectivamente, aparecem na documentação registros de duas denegações consecutivas a embargos impetrados por Manoel Luiz Maria e sua esposa, às sentenças que Ihe haviam sido desfavoráveis ${ }^{30}$.

\footnotetext{
${ }^{29}$ Ibid.

${ }^{30}$ TJMG - PROCESSO No 02490747829-1, maço 33 - Cópia dos Autos, p. 102-102v; 111-111v; 126.
} 
Ora, se os acontecimentos que geraram o Inquérito Policial em apreço ocorreram no dia 6 de julho de 1915, de fato os herdeiros são coerentes ao afirmarem que não havia decisão definitiva da Justiça a respeito das terras em litígio. Observemos a insistência de Manoel em interpor recursos e embargos às decisões iniciais do Tribunal de Relação quanto às duas ações. No dia 3 de julho de 1915, é provável que ele tenha sido intimado a comparecer a juízo para ser informado dos resultados das sentenças, ou mesmo de depor sobre algum aspecto que necessitasse de esclarecimento, para a avaliação dos embargos. É plausível, ainda, que no dia 6 de julho ele, de fato, estivesse ausente da Bom Sucesso, atendendo à intimação que recebera recentemente. De forma que os G. R. teriam se equivocado - ou agido de má-fé - ao construírem a cerca antecipando-se, ante uma interpretação equivocada de que a visita de um oficial de justiça a Manoel teria sido para comunicar decisão da justiça em seu próprio favor. Desse modo, parecem procedentes os testemunhos de Joaquim Luiz, Joaquim Mendes e de Agostinho Rodrigues, a seguir, que atestaram a ausência de Manoel junto ao grupo dos herdeiros que retiraram a cerca recémconstruída pelos G. R. no terreno ainda em litígio.

Observemos, pois, o depoimento de Joaquim Luiz Marcellino, 34 anos, filho de Manoel, em 20 de julho de 1915, ao Delegado Waldemar Loureiro:

de facto, o declarante e todos constantes da relação que the foi apresentada e lida, inclusive mais uns menores [...], desmancharam uma cerca feita em certo logar dos ditos terrenos, logar em que nunca houve cerca alguma; que isso fizeram não só porque nunca houve a cerca alli como também não foram intimados de sentença alguma judicial, mas sim por se achar o pai do declarante no Forum, nesta Capital, no tres do corrente, o que elle de facto fez, que a cerca não foi demolida, mas sim mudada para o logar primitivo, que foi 0 que fizeram; que o pai do declarante, de nome Manoel Luis, não cheffiou o grupo que alli foi, não tendo mesmo ido ao local conforme dis [sic] o officio do subdelegado dalli. Perguntado mais, respondeu que o declarante e todos os constantes da rellação que Ihe foi lida, teem direito nas ditas terras, achando-se no fórum os documentos a esse respeito ${ }^{31}$.

Além de assumir o feito, considerado justo pelos herdeiros, já que "nunca houve a cerca ali", nem "foram intimados de sentença alguma judicial", Joaquim Luiz informa sobre a presença do pai, Manoel Luiz - formalmente acusado de estar presente junto ao grupo e de chefiá-lo - no Fórum, atendendo a chamado da Justiça, no mesmo momento do episódio da cerca.

O depoimento de Joaquim Mendes, um dos companheiros de José Luiz Maria, é ainda mais elucidativo, ao acrescentar que:

não tendo havido nenhuma intimação judicial para a entrega dos ditos terrenos, acharam que não devia ser feita a cerca que J. G. $R$. construiu e por isso desmancharam a mesma,

${ }^{31}$ Ibid. (Grifos meus). 
mudando-a para o primitivo logar, deixando apenas no chão a sobra de arame e estacas arrancadas, que de facto o declarante e os demais companheiros, todos representados por Manoel Luiz, foram intimados a vir no Forum, no dia tres do corrente, o que Manoel Luis fez; que não foram intimados para pagamento das custas nem sabem de tal decisão judicial. Perguntado mais, respondeu que Manoel Luiz não fez parte do grupo que foi arrancar a cerca e que o grupo não tinha chefe, pois que todos que fasiam [sic] parte do mesmo são interessados na causa relativa as terras. ${ }^{32}$

A última parte do depoimento de Mendes faz emergir, do Inquérito, um contraponto importante às percepções que os G. R. e outros contemporâneos possuíam sobre os herdeiros: eles não precisavam de ninguém que os "chefiasse", apresentavam-se como um grupo coeso ante o objetivo comum de garantir os próprios interesses, que eram coletivos, já que todos que dele participavam eram "interessados na causa relativa as terras." A expressão dessa coesão fica mais evidente, ao considerarmos a ação simultânea de Manoel Luiz Maria ${ }^{33}$ e Ana Apolinária, provavelmente reconhecidos e respeitados pelos seus como patriarca/matriarca e representantes, junto à Justiça.

Certo caráter de dignidade também fica registrado na forma como os acusados se portam e na maneira como respondem à polícia: reconhecem terem retirado a cerca, mas não entendem isso como crime, visto considerarem que a disputa judicial ainda não havia sido encerrada e que, portanto, se alguém cometera alguma irregularidade teriam sido os G. R., ao tentarem redefinir os limites das terras, sem anuência formal da Justiça. Note-se, nesses depoimentos, a propósito, a recorrência da manifesta confiança até então depositada por Manoel, Ana Apolinária e os seus no recurso jurídico.

O Inquérito parece inconcluso, mas, talvez, tenha sido o mesmo encaminhado ao Delegado Especial de Polícia, Viriato Mascarenhas que, devido a uma petição assinada por J. G. R., afirmou em juízo ter intimado Manoel Luiz Maria, em meados do mês de julho daquele ano de 1915, e o exortado "a evitar violências" e que ouviu, ainda, de Manoel a afirmação de que possuía terras na Fazenda Bom Sucesso ${ }^{34}$.

Desde então, até o assassinato de A. C., em 31 de outubro de 1916, o conflito entre os dois grupos que dividiam a Bom Sucesso parece ter se agravado - especialmente após a admissão formal de A. C. como Procurador dos herdeiros, a partir de agosto de 1915. Nos depoimentos das testemunhas de defesa dos acusados pelo assassinato do italiano, destaca-se a tendência em descrevê-lo como responsável pelos "ataques" dos herdeiros às terras em

\footnotetext{
${ }^{32}$ Ibid. (Grifos meus).

33 Manoel Luiz estaria, então, com 53 anos de idade, considerando que em 1902, contava 40 anos.

34 TJMG - PROCESSO No 02490747829-1, maço 33 - Cópia dos Autos Cíveis no 3.387 referentes ao Mandado Executivo passado a favor de H.G. R. e sua mulher e outros - contra Manoel Luiz Maria e sua mulher, p. 106.
} 
litígio, mas que os G. R. julgavam como suas ${ }^{35}$. Em nenhum dos depoimentos, contudo, faz-se referência ao episódio de 6 de julho de que tratamos acima, ocorrido antes da oficialização de A. C. como Procurador dos herdeiros. Os depoimentos em questão, colhidos três dias após crime por meio do qual F. G. R. tirara a vida a A. C., foram feitos possivelmente mediante orientação do advogado Gudesteu Pires de Sá, sendo provável que tenham sido construídos já como parte da estratégia de defesa dos acusados - então foragidos. Talvez por isto o que eles ressaltem seja a atuação da própria vítima, enquanto negociante -, responsabilizando-a pelo alegado móvel do crime, que teriam sido as "desordens" cometidas pelos herdeiros, sob suposta orientação do italiano.

A estratégia do advogado foi bem-sucedida e, embora o réu principal - $F$. G. R. - tenha sido considerado culpado em todas as instâncias da investigação e do julgamento, até a fase do júri, ao final foi absolvido, sob as seguintes alegações: 1) o réu era menor de idade; 2) cometera o crime em defesa de sua honra e da propriedade. Sobre esta última, o júri foi facilmente convencido, a partir da campanha de detração da figura da vítima, promovida pelo advogado, durante a atuação da defesa, ao longo do Processo. Essa estratégia era sustentada, ainda, por meio do esforço de desqualificação dos depoimentos das testemunhas representadas pelos herdeiros, que inclusive nesse momento continuavam a reiterar serem possuidores de parte das terras da Fazenda Bom Sucesso, apontando A. C. como interlocutor que agia em prol do interesse do grupo $^{36}$.

Ao investigar a trajetória de Manoel Luiz Maria e seus companheiros, nas fontes arquivísticas disponíveis, deparamos com um grupo de pessoas negras, que empreendem com firmeza e lançando mão dos recursos que lhe são possíveis, a defesa do que entendem serem direitos seus - seja o de não sofrer abuso de poder por parte de autoridade alguma, nem mesmo da polícia; seja o de viver em paz em suas terras.

Trata-se de um caso até então inédito na historiografia sobre Belo Horizonte, e que se enuncia como um marco de ruptura numa tradição discursiva sobre a cidade que, em aparente paradoxo, tem produzido silêncios e invisibilidades ao negligenciar a abordagem da presença de determinados sujeitos na história da cidade. Ana Apolinária, Manoel Luiz, seus filhos Joaquim Luiz Marcelino, Jose Luiz Maria; Joaquim, Henrique Mendes e outros de suas famílias, afinal, são referenciados em um dos mais importantes casos que tiveram lugar na ainda jovem Capital do Estado de Minas Gerais. Eles podem ser considerados como uma espécie de testemunho das continuidades que ligavam o antigo Arraial do Curral Del Rei e a nova cidade, que se pretendia moderna e republicana; ao mesmo tempo em que são impactados pelas mudanças provocadas pelos novos tempos que as elites mineiras buscavam impor por meio da criação da nova cidade.

Com efeito, é notável que durante tanto tempo - entre 1856, quando a fazenda foi dividida e meados de 1912 - as relações entre os herdeiros e os G.

\footnotetext{
35 TJMG - PROCESSO No 02490747829-1, maço 33 - Inquérito Policial referente ao assassinato de A. C. 3/11/1916, p. 25-26v.

${ }^{36}$ TJMG - PROCESSO No 02490747829-1, maço 33.
} 
R., na Fazenda Bom Sucesso, tenham ocorrido aparentemente sem percalços. Entretanto, com a transferência da capital do Estado para o Arraial do Curral Del Rei, aquelas terras passaram a ser valorizadas economicamente, considerada a riqueza de recursos hídricos e minerais da região. De tal sorte que também o Governo do Estado tinha interesses em explorar tais recursos e para tanto, assim como fizera com as Fazendas do Barreiro, do Cercadinho e outras da região, buscava negociar a compra dos terrenos dos quais se pudesse explorar água e outros recursos para abastecer a nova cidade. Também a The Saint Jonh d'El Rei Mining tinha interesses em partes dos terrenos da Bom Sucesso, de modo que também havia sido acionada na Justiça pelos herdeiros, por estar ocupando, ao que parece indevidamente, tais terras ${ }^{37}$. Diante desse novo cenário, é plausível aventar que os G. R., provavelmente bem informados acerca dessa nova possibilidade de negócios e valendo-se de um equivocado pressuposto acerca de incapacidade e ignorância de seus vizinhos - negros e analfabetos - tentaram apropriar-se indevidamente de parte das terras destes.

O fato é que, a despeito do favorecimento da Justiça aos G. R., entre 1914 e 1917 - tanto no caso dos Processos Cíveis envolvendo as terras do Bom Sucesso quanto no Processo Criminal pelo assassinato de A. C. -, os enfrentamentos dos herdeiros em defesa de suas terras se estenderam ao longo do tempo: há indícios de que dentre aquelas 79 pessoas, outorgantes da Procuração lavrada em favor de A. C., figuram nomes que constam de um depoimento recente da inventariante de um dos três quilombos urbanos de Belo Horizonte e que herdou o nome de "Luízes", em clara referência à ancestralidade que remete à geração de Ana Apolinária e Manoel Luiz. ${ }^{38}$ Mas esta já é outra parte da história, que os limites deste artigo não nos permitem explorar.

\section{Sobre a autora}

Josemeire Alves Pereira é doutoranda em História na Universidade Estadual de Campinas (Unicamp). E-mail: josemeire@gmail.com.

Artigo recebido em 30 de janeiro de 2016.

Aprovado em $1^{\circ}$ de julho de 2016.

\footnotetext{
${ }^{37}$ Ibid.

${ }^{38}$ Cf. AMARAL, Juliano Bernardes do. Lágrimas da Liberdade: relatos de resistência de uma comunidade quilombola urbana, o quilombo dos Luízes. 2014. Dissertação (Mestrado em Direito). Faculdade Mineira de Direito, Pontifícia Universidade Católica de Minas Gerais. Belo Horizonte, 2014.
} 